\title{
OS DESAFIOS EDUCACIONAIS PARA ATENDER OS ALUNOS EM SITUAÇÃO DE EXCLUSÃO
}

\author{
Joselita Silva Medeiros ${ }^{1}$ \\ Marcia Diana Jesus Oliveira²
}

\section{RESUMO}

O objetivo geral desta pesquisa foi apresentar as implicações da exclusão educacional. Os objetivos específicos foram apresentar os fatores referentes à educação e pobreza, demonstrar as definições de inclusão e exclusão educacional e demonstrar os fatores concernentes à inclusão social no âmbito escolar. A metodologia consistiu em uma revisão de literatura, de caráter exploratório, descritivo e qualitativo. A problemática desta pesquisa consiste no seguinte questionamento: é atenuar as consequências da exclusão educacional? Concluiu-se que é importante a participação da família, da escola e de profissionais em um caráter multidisciplinar, com vistas a propiciar a inclusão educacional em circunstâncias semelhantes.

Palavras chave: Inclusão. Exclusão. Educação. Sociedade.

\section{ABSTRACT}

The general objective of this research was to present the implications of educational ${ }^{1}$ exclusion. The specific objectives were to present the factors related to education and poverty, to demonstrate the definitions of educational inclusion and exclusion and to demonstrate the factors related to social inclusion in the school environment. The methodology consisted of a literature review, exploratory, descriptive and qualitative. The problem of this research consists of the following question: is it to mitigate the consequences of educational exclusion? It was concluded that the participation of the family, the school and professionals in a multidisciplinary nature is important, with a view to promoting educational inclusion in similar circumstances.

Keywords: Inclusion. Exclusion. Education. Society.

\section{INTRODUÇÃO}

A situação da pobreza no país leva à exclusão social, promovendo o distanciamento e a exclusão educacional; dessa forma, esta temática, que é pouca discutida e estudada, não é prioridade nas ações governamentais. Somos

\footnotetext{
${ }^{1}$ Mestranda em Ciências da Educação na Faculdade Interamericana de Ciências Sociais - FICS. Graduada em Pedagogia na Faculdade de Educação - Faced /UFBA. Docência e coordenação no Ensino Fundamental e Educação Infantil. E-mail: joselitamedeiros44@gmail.com.

2 Mestranda do curso de Mestrado em Ciências da Educação, Graduada em Pedagogia e pósgraduada em Psicopedagogia, Gestão e Coordenação Escolar e Educação Infantil. Funcionária Pública da Rede Municipal de São Francisco do Conde-Ba, atualmente no Departamento Administrativo da Secretaria de Educação. E-mail: marciadi.pedagoga@gmail.com
} 
reconhecidos mundialmente como um país gerador de riquezas imensas, mas figuramos quase que nos últimos lugares nos indicadores avaliativos nacionais e internacionais e nas estatísticas sobre a qualidade de vida da população.

O Brasil também ocupa um dos últimos lugares na avaliação do PISA que trata de avaliar alunos do Ensino Fundamental nas disciplinas de Português, Matemática e Ciências (BRASIL, 2012).

Neste diapasão, a educação continua servindo as classes sociais abastadas, de maneira que a parcela da população mais carente é relegada ao ensino precário. Os fatores sociais predicantes mostram-se acrescidos por diversos dispositivos ocorrentes no sistema educacional, como a carência de investimento do poder público na formação do aluno, promovendo, desta feita, a extensão de sua condição socialmente carente à escola, de maneira que o estudo não torna-se um estímulo e sim uma atividade extra ao seu cotidiano, haja vista que, no ambiente escolar, as circunstâncias são as mesmas verificadas em seu ambiente doméstico, todavia, é necessário considerar que há alunos que dirigem-se ao ambiente escolar almejando ausentar-se das condições hostis de seus lares.

O objetivo geral desta pesquisa foi apresentar as implicações da exclusão educacional tendo em vista as deficiências cognitivas. Os objetivos específicos foram apresentar os fatores referentes à educação e as deficiências cognitivas, demonstrar as definições de inclusão e exclusão educacional e demonstrar os fatores concernentes à inclusão social no âmbito escolar. A metodologia consistiu em uma revisão de literatura, de caráter exploratório, descritivo e qualitativo.

A problemática desta pesquisa consiste no seguinte questionamento: é possível atenuar as consequências da exclusão educacional?

Esta pesquisa é uma revisão de literatura, de natureza exploratória. Severino (2011, p. 123), afirma, sobre a pesquisa exploratória, que esta modalidade de pesquisa "é uma preparação para a pesquisa explicativa", ou seja, este tipo de pesquisa almeja revelar dados acerca de um objeto, com campo de trabalho restrito, observando-se como se dá a pronúncia deste elemento.

\section{INCLUSÃO E EXCLUSÃO EDUCACIONAL}

A exclusão educacional não se dá casualmente; basta analisar a história do Brasil, para verificar que toda a sequência de fatos históricos foi fruto da ação dos 
colonizadores, os quais desconsideraram a cultura indígena e dos negros africanos escravizados, impondo a esses os próprios costumes. Vale destacar que. “... todos os grandes acontecimentos desta era, a que se convencionou chamar com razão de 'descobrimentos', articulam-se num conjunto que não é senão um capítulo da história do comércio europeu" (PRADO, 1973, p. 14).

Posteriormente, o referido autor afirma que o mercantilismo, vigente à época, influenciou a síntese da atual sociedade, dizendo que:

Se vamos à essência da nossa formação, veremos que na realidade nos constituímos para fornecer açúcar, tabaco, alguns outros gêneros; mais tarde ouro e diamante; depois algodão, e em seguida café, para o comércio europeu. Nada mais que isso (Ibid., p. 23).

Assim, perante esta sequência de fatos históricos, é possível compreender o porquê de a sociedade brasileira ter a característica predominante da desigualdade.

No decorrer da exploração europeia, o colonizador sentiu a necessidade de implementar latifúndios caracterizados pela monocultura, utilizando plenamente os negros africanos e visando escravizar também os índios. Nesses moldes, se deu todo o período do Brasil colonial, tanto na ocupação do litoral quanto do interior. A dominação se deu com a instalação da estrutura sócio-política dominante, a qual reinava sobre uma maioria massacrada e paupérrima, ou seja, a exclusão social já era vislumbrada.

Visando alcançar tecnologia de caráter militar, há a gênese de alguns cursos, os quais originariam, posteriormente, os primeiros cursos superiores brasileiros, pois:

É em razão da defesa militar que são criadas, em 1808, a Academia Real da Marinha e, em 1810, a Academia Real Militar (que em 1858, passou a chamar-se Escola Central; em 1874, Escola Politécnica, e hoje é a Escola Nacional de Engenharia), a fim de que atendesse à formação de oficiais e engenheiros civis e militares. Em 1808 é criado o curso de cirurgia (Bahia), que se instalou no Hospital Militar, e os cursos de cirurgia e anatomia, no Rio. No ano seguinte, nesta mesma cidade organiza-se o de medicina. Todos esses visão atender à formação de médicos e cirurgiões para o exército e a marinha (RIBEIRO, 2001, p. 41).

A educação fora ampliada, contudo, não atendia ao povo, mas apenas às elites econômicas, ou seja, desde os primórdios da instalação de um sistema educacional no Brasil, o caráter já era segregador: vislumbrava-se o embrião da exclusão educacional, que cristalinamente efetivou-se na atualidade.

A falta de estímulo à leitura é um fator determinante para o total desconhecimento por parte dos alunos em relação à biblioteca da escola. Os alunos 
por sua vez alegam que mesmo sabendo que ali funciona a biblioteca da escola, afirmam que não gostam muito de ler e também não tem tempo para a prática da leitura e ainda reforçam que os assuntos que caem em suas avaliações não constam naqueles livros e que isso, por sua vez, não desperta o interesse neles em consultá-los.

Paulo Freire (2001) afirma que na Escola Bancária, o professor é o detentor de todo o conhecimento, que promove longos discursos em suas aulas, forma e sedimenta a escola tradicional, caracterizada pelo aluno que não tem conhecimento e que é passivo. Não há abertura ao diálogo, não há debates entre professor e aluno nem entre os próprios alunos. Afirma o educador:

\begin{abstract}
A programação desses debates nos era oferecida pelos próprios grupos, através de entrevistas que mantínhamos com eles e de que resultava a enumeração de problemas que gostariam de debater. 'Nacionalismo', 'Remessa de lucros para o estrangeiro', 'Evolução política do Brasil', 'Desenvolvimento', 'Analfabetismo', 'Voto do Analfabeto', 'Democracia', entre outros, temas que se repetiam, de grupo a grupo (FREIRE, 2001, p. 158).
\end{abstract}

No âmbito da exclusão educacional, faz-se necessário discorrer acerca do Rendimento (ou Eficiência dos Sistemas de Ensino), que é a propriedade de transmutar o acesso à educação em realização, ou seja, considerando que as pessoas em idade escolar consigam o acesso às instituições educacionais, refere-se à conversão desse acesso ao período temporal determinado no qual o indivíduo deve permanecer na escola, cumprindo o tempo correto de cada série, ano ou nível. É correto dizer que um sistema educacional possui rendimento satisfatório quando as crianças obtêm: Conclusão do nível médio num período de três anos; Conclusão do nível fundamental em nove anos.

Hasenbalg e Valle Silva (2000) identificaram pontos de presença constante na desigualdade educacional: o aperfeiçoamento da qualidade de vida $-60 \%$ - foi mais relevante que as políticas educacionais - $40 \%$ - no aprimoramento do sistema educacional, todavia, os autores afirmam que na década de 1990, verificou-se a dilatação da conjuntura educacional, dizendo os autores que "observa-se que as medidas de correção de fluxo adotadas tiveram um claro impacto nestes fluxos, com uma diferenciação de comportamento entre as décadas estudadas" (HASENBALG; VALLE SILVA, 2004, p. 125).

De acordo com a Teoria da Desigualdade Maximamente Mantida, tornar certa conjunção social democrática, atingir um âmbito restrito de qualificação é possível 
exclusivamente com a generalização dos níveis precedentes, de maneira que os indivíduos que inicialmente se beneficiaram - logicamente - estão à frente de todos, ou seja, a elite dominante, desde a época colonial, se beneficiou do sistema educacional e tal fato perpetuou-se até os dias atuais:

Parece plausível imaginar que os principais beneficiários da expansão educacional no Brasil, que se concentrou sobretudo nos níveis intermediários de ensino (dado que o acesso já se havia universalizado no início do período da expansão), foram os grupos já em situação de relativa vantagem (HASENBALG; VALLE SILVA, 2004, p. 132).

A proficiência escolar provê a aprendizagem e é sua finalidade definitiva, contudo, não é a única, no âmbito das políticas educacionais. O desempenho, sinônimo de proficiência, significa transformar a permanência (na escola) em aprendizagem efetiva, seja no âmbito da atividade intelectual ou técnica, visando o desenvolvimento da sociedade, fazendo valer o investimento público na sua educação.

\section{INCLUSÃO SOCIAL NA ESCOLA}

A exclusão social é um fenômeno que anseia pela aplicação do paradigma da inclusão social. Pina e Martins (2010) efetuaram uma pesquisa acerca do tema, com a conclusão de que a exclusão não provém das relações sociais de produção e constatando, no mesmo estudo, que não se pode sanar a exclusão social sem suplantar as relações do capitalismo. Partindo do sentido sinalizado pelos autores apresentados na Tabela 1, surge o questionamento acerca do interesse da inclusão social necessitar ou não suplantar a exclusão social.

Tabela 1: Diversidade de entendimentos

\begin{tabular}{|l|c|}
\hline \multicolumn{1}{|c|}{ Inclusão social } & Fonte \\
\hline $\begin{array}{l}\text { Processo que garante que as pessoas em risco de pobreza e exclusão } \\
\text { social acedam às oportunidades e aos recursos necessários para } \\
\text { participarem plenamente nas esferas económica, social e cultural e } \\
\text { beneficiem de um nível de vida e bem estar considerado normal na } \\
\text { sociedade em que vivem. }\end{array}$ & COM, 2003, p. \\
\hline $\begin{array}{l}\text { São as políticas sociais contemporâneas que priorizam, equivocadamente, } \\
\text { atingir os excluídos que estão no limite das privações através de programas } \\
\text { focalizados que sustentam rótulos de "inclusão social”. }\end{array}$ & $\begin{array}{c}\text { Lopes, 2006, p. } \\
\text { Processo que visa promover a inclusão dos segmentos em vulnerabilidade } \\
\text { Pocial, destacando a cidade, a escola, o emprego e a proteção social. }\end{array}$ \\
\hline
\end{tabular}




\begin{tabular}{|l|c|}
\hline $\begin{array}{l}\text { Refere se à solidariedade social que é um processo diferente da exclusão } \\
\text { social, pois reflete companheirismo. }\end{array}$ & $\begin{array}{c}\text { Barry, 1998, p. } \\
17\end{array}$ \\
\hline $\begin{array}{l}\text { A inclusão social de grupos não é meramente simbólica, já que também } \\
\text { contém implicações económicas. }\end{array}$ & $\begin{array}{c}\text { Silver, 2005, p. } \\
138\end{array}$ \\
\hline $\begin{array}{l}\text { É uma questão de abertura e de gestão: abertura, entendida como } \\
\text { sensibilidade para identificar e recolher as manifestações de insatisfação e } \\
\text { dissensos sociais, para reconhecer a "diversidade" social e cultural; gestão, } \\
\text { entendida como crença no caráter quantificável, operacionalizável, de tais } \\
\text { demandas e questionamentos, administráveis por meio de técnicas } \\
\text { gerenciais e da alocação de recursos em projetos e programas (as políticas } \\
\text { públicas). }\end{array}$ & $\begin{array}{c}\text { Laclau, 2006, } \\
\text { p. 28 }\end{array}$ \\
\hline $\begin{array}{l}\text { Processo pelo qual a exclusão social é amenizada. Caracteriza se pela } \\
\text { busca da redução da desigualdade através de objetivos estabelecidos que } \\
\text { contribuam para o aumento da renda e do emprego. }\end{array}$ & $\begin{array}{l}\text { Wixey et al., } \\
2005, p .16\end{array}$ \\
\hline $\begin{array}{l}\text { A inclusão social está relacionada com a procura de estabilidade social } \\
\text { através da cidadania social, ou seja, todos os cidadãos têm os mesmos } \\
\text { direitos na sociedade. A cidadania social preocupa se com a } \\
\text { implementação do bem estar das pessoas como cidadãos. }\end{array}$ & $\begin{array}{c}\text { Sheppard, } \\
2006, p .22\end{array}$ \\
\hline
\end{tabular}

Fonte: BORBA, 2006.

Destaca Sassaki que a inclusão social "[...] é a construção de uma sociedade realmente para todas as pessoas, sob a inspiração de novos princípios" (SASSAKI, 1999, p.17). Afirma que a consideração das diversidades, o direito de pertencer, a celebração das divergências entre os seres humanos, solidariedade, elevação das minorias e respeito à cidadania são princípios que merecem destaque quando se visa à inclusão social. Vale destacar que:

Conceitua-se inclusão social como o processo pelo qual a sociedade se adapta para poder incluir, em seus sistemas sociais gerais, pessoas com necessidades especiais e, simultaneamente, estas se preparam para assumir seus papéis na sociedade. A inclusão social constitui, então, um processo bilateral no qual as pessoas, ainda excluídas, e a sociedade buscam, em parceria, equacionar problemas, decidir sobre soluções e efetivar a equiparação de oportunidades para todos (Ibid, p.41).

Conceituar inclusão social implica o desejo de extirpar a exclusão, fazendo surgir na sociedade um processo adaptativo, no qual é possível incluir os cidadãos que se encontram às margens sociais, de forma que é uma progressão perante a exclusão. Afirma-se que "[...] para incluir todas as pessoas, a sociedade deve ser modificada a partir do entendimento de que ela é que precisa ser capaz de atender às necessidades de seus membros" (Id., 2005, p. 21). Demonstra-se, na citação, a evidência de que o problema está na característica excludente da sociedade e não no ser humano que for excluído, quebrando o paradigma de que o problema era aquele que estava à margem e não a sociedade que o excluíra. 
Tal padrão livrava a sociedade de justificar a razão pela qual o excluído encontrava-se em dada circunstância e relegava-se exclusivamente a este a responsabilidade de sua condição, portanto, surgiu a conclusão de que devem haver mudanças sociais, no sentido de ceifar os fatores promoventes da exclusão, uma vez que:

\begin{abstract}
A inclusão consiste em adequar os sistemas sociais gerais da sociedade de tal modo que sejam eliminados os fatores que excluam certas pessoas do seu seio e mantinham afastadas aquelas que foram excluídas. A eliminação de tais fatores deve ser um processo contínuo e concomitante com o esforço que a sociedade deve empreender no sentido de acolher todas as pessoas, independentemente de suas diferenças individuais e das suas origens na diversidade humana (SASSAKI, 2005, p.21).
\end{abstract}

O autor afirma que a origem do paradigma da inclusão provém do fato de que quando uma organização não-governamental sintetizada por líderes com deficiência - a Disabled Peoples'International - identificou a equiparação de oportunidades. Tal definição consiste como sendo:

\begin{abstract}
O processo mediante o qual os sistemas gerais da sociedade, tais como 0 meio físico, a habitação e o transporte, os serviços sociais e de saúde, as oportunidades de educação e de trabalho, e a vida cultural e social, incluídas as instalações esportivas e de recreação, são feitos acessíveis para todos. Isto inclui a remoção de barreiras que impedem a plena participação das pessoas deficientes em todas estas áreas, permitindo-Ihes assim alcançar uma qualidade de vida igual à de outras pessoas (DRIEDGER; ENNS apud SASSAKI, 1999, p.39).
\end{abstract}

Aparentemente, a chamada equiparação de oportunidades pode ser considerada um avanço, pois:
A discussão sobre educação inclusiva envolve a relação exclusão e inclusão que ganha tonalidades diferentes e altera políticas sociais, impondo uma nova ética e uma moral que justificam o controle de tecnologias, o monopólio de riquezas, o domínio das informações, a circulação de conhecimento, a seleção de benefícios, a delimitação dos territórios e as possibilidades de melhorias de vida (BORDAS. et al, 2009, p.10).

Sobretudo porque as modificações defendidas por esse processo podem atender às necessidades imediatas de algumas pessoas que estariam impedidas de ocupar alguns ambientes, caso tais modificações não fossem realizadas

\title{
CONSIDERAÇÕES
}

Em observação ao aporte teórico constante nesta pesquisa, constatou-se que o corpo docente das instituições em geral se mostra plenamente disponíveis para suprir as demandas dos alunos. Este trabalho é proveniente da necessidade de 
refletir a respeito das práticas pedagógicas a respeito da inclusão educacional, na concernente manutenção dos alunos na sala de aula, na satisfação de suas necessidades diversas, assim como no nivelamento das oportunidades de aprendizagem dos concernidos educandos em referência aos demais alunos.

Considerando-se o relato de caso demonstrado, tem-se que a interação entre família e escola, assim como a participação multiprofissional, é elementar para o desenvolvimento e inclusão de indivíduos com deficiência cognitiva, de forma que o trabalho em conjunto, nestes três âmbitos, apresenta contribuições ao desenvolvimento do indivíduo.

É de grande importância enfatizar a importância da família, como ente de respaldo ao aluno em situação de exclusão educacional. No ambiente escolar, o corpo docente deve prover os recursos e práticas necessárias ao atendimento às necessidades do aluno, atenuando, desta maneira, as limitações que impedem a prática do conhecimento ao mesmo ritmo dos demais alunos. Deve o professor respeitar o citado ritmo, considerando-se que a exclusão educacional apresenta implicações que atuam na integralidade do indivíduo, comprometendo aspectos psicológicos e cognitivos.

\section{REFERÊNCIAS}

BORBA, A.A. Exclusão e inclusão social nas sociedades modernas: um olhar sobre a situação em Portugal e na União Europeia. Serv. Soc. Soc., São Paulo, n. 106, p. 219-240, abr./jun. 2011.

BORDAS, M. et al. Educação inclusiva, deficiência e contexto social: questões contemporâneas. Salvador: EDUFBA, 2009.

BRASIL. Constituição Federal do Brasil. 1988.

BRASIL. LDB. Lei de Diretrizes e Bases da Educação Nacional. Presidência da República. Brasília. DF. 1996.

BRASIL. Ministério da Educação. INEP. Brasília, DF. 2011.

BRASIL. Ministério da Educação. Plano Decenal de Educação para Todos. Brasília, DF: MEC, 1993.

BRASIL. Ministério da Educação. Secretaria de Educação Básica. Caderno 1 Conselhos Escolares: democratização da escola e construção da cidadania. Brasília - DF, 2004; 
CARVALHO, A.; DIOGO, F. Projeto educativo. Edições Afrontamento, Porto. 1999.

CUNHA, L. A. Educação e desenvolvimento social no Brasil. Rio de Janeiro: Francisco Alves, 1975a

FREIRE, P. Educação como prática da liberdade. 25. ed. São Paulo: Paz e Terra, 2001. $158 \mathrm{p}$.

KOWARICK, L. Sobre a vulnerabilidade socioeconômica e civil - Estados Unidos, França e Brasil, Revista Brasileira de Ciências Sociais, São Paulo, v. 18, n. 51, p. $6185,2003$.

LACLAU, E. Inclusão, exclusão e a construção de identidades. In: AMARAL JR, Aécio; BURITY, Joanildo (Orgs.). Inclusão social, identidade e diferença: perspectiva pós estruturalista de análise social. São Paulo: Annablume, 2006.

LOPES, J. R. Exclusão social e controle social: estratégias contemporâneas de redução da sujeiticidade. Psicologia \& Sociedade. Florianópolis, v. 18, n. 2, p. 1324 , 2006

MARTINS, J. Estudos sobre existencialismo, fenomenologia e educação. São Paulo: Centauro, 2006.

PINA, L. D.; MARTINS, A. S. Implicações da crise capitalista no campo teórico: pós-modernidade e exclusão social das pessoas com deficiência. Trabalho necessário, v.10, p.1-29. São Paulo, 2010.

RIBEIRO, P. S. Preconceito de classe social; Brasil Escola. Disponível em http://brasilescola.uol.com.br/sociologia/preconceito-classe-social.htm. Acesso em 29 nov 2019.

SANTOS, G. L.. Educação ainda que tardia: a exclusão da escola e a reinserção de adultos das camadas populares em um programa de EJA. Rev. Bras. Educ. no.24 Rio de Janeiro Sept./Dec. 2003.

SASSAKI, R. K. Inclusão. Construindo uma sociedade para todos. Rio de Janeiro: WVA, 1999.

SASSAKI, R. K. Inclusão: o paradigma do século XXI. Inclusão. Revista da Educação especial. v. 1, n. 1, p.19-23. 2005.

SILVER, H. Políticas dos países europeus para promover a inclusão social. In: BUVINIC, M.; MAZZA, J.; DEUTSCH, R. (Orgs.). Inclusão social e desenvolvimento econômico. Rio de Janeiro: Elsevier, 2005

VALLE SILVA, N. Expansão Escolar e Estratificação Educacional no Brasil. In: Carlos Hasenbalg; Nelson do Valle Silva. (Org.). Origens e DestinosDesigualdades Sociais ao Longo da Vida. 1 ed., v. 1, p. 105-146.. Rio de Janeiro: TopBooks, 2003. 